\title{
Initial Oxygenation Response to Inhaled Nitric Oxide Predicts Improved Outcome in Congenital Diaphragmatic Hernia
}

\author{
Sibel Tiryaki $\cdot$ Coskun Ozcan $\cdot$ Ata Erdener
}

Published online: 20 September 2014

(c) The Author(s) 2014. This article is published with open access at Springerlink.com

\begin{abstract}
Background Pulmonary hypertension ( $\mathrm{PH})$ is the most important complication of congenital diaphragmatic hernia $(\mathrm{CDH})$ and still has a high mortality rate. The aim of this study was to evaluate the effectiveness of inhaled nitric oxide therapy in $\mathrm{PH}$ due to $\mathrm{CDH}$.

Methods Hospital records of children who had undergone inhaled nitric oxide therapy for PH due to $\mathrm{CDH}$ between June 2009 and December 2011 were reviewed.

Results Twenty-nine patients had a diagnosis of $\mathrm{CDH}$ at the time of study, and eight of these patients underwent nitric oxide therapy because of failure of conventional ventilation techniques, which was successful in five of these patients. Patients who had a good overall outcome of nitric oxide therapy experienced rapid improvement (pretreatment, mean $\mathrm{PaO}_{2}=44.8 \mathrm{mmHg}$; after the first hour of therapy, mean $\mathrm{PaO}_{2}=96.8 \mathrm{mmHg}$ ), whereas patients with no response did not have a similar course (pretreatment, $\mathrm{PaO}_{2}=37 \mathrm{mmHg}$; after the first hour, $\mathrm{PaO}_{2}=$ $54.6 \mathrm{mmHg}$ ).

Conclusion Inhaled nitric oxide therapy seems to increase survival in $\mathrm{PH}$ due to $\mathrm{CDH}$. No predictive parameters to orient patient selection could be identified; however, the early response seemed to predict the overall outcome. Good results in our series were attributed to routine use of sildenafil and dopamine, along with the nitric oxide inhalation.
\end{abstract}

\footnotetext{
S. Tiryaki $(\bowtie)$

Hacettepe University, Ankara, Turkey

e-mail: tiryakisibel@gmail.com

C. Ozcan · A. Erdener

Ege University, Izmir, Turkey
}

\section{Introduction}

Nitric oxide is a potent vasodilator, which acts through guanylyl cyclase activation, leading to production of cyclic guanosine monophosphate and therefore smooth muscle relaxation [1]. Inhaled nitric oxide (iNO) serves as the only selective pulmonary vasodilator available today, and several studies have shown that it improves the outcome of newborns with pulmonary hypertension (PH) [2-8]. Although $\mathrm{PH}$ due to congenital diaphragmatic hernia $(\mathrm{CDH})$ has been suggested to have a similar pathophysiological mechanism, published results of iNO therapy in such cases have not been as good as expected. The only randomized trial [9] failed to show any benefit and, despite widening usage of this therapy, the literature still consists of conflicting reports [10-18]. The aim of this study was to evaluate our results with iNO therapy for $\mathrm{PH}$ due to $\mathrm{CDH}$.

\section{Patients and Methods}

Hospital records of children who had undergone iNO therapy for PH due to CDH from June 2009 to December 2011 were reviewed. As a part of our institution's protocol for $\mathrm{CDH}$, all patients with signs of $\mathrm{PH}$ were intubated, and bedside central venous catheterization and umbilical arterial catheterization were performed immediately. Dopamine infusions $(5 \mu \mathrm{g} / \mathrm{kg} / \mathrm{min})$ and sildenafil $(0.5 \mathrm{mg}$ four times daily, administered enterally via the nasogastric tube) were started. Our initial management includes pressurecontrolled ventilation in the synchronized intermittent mandatory mode, adhering to the concept of gentle ventilation with permissive hypercapnia in $\mathrm{CDH}$. This involves keeping pressure settings at the lowest levels (peak inspiratory pressure $[\mathrm{PIP}]<25 \mathrm{mmHg}$ ), providing a partial 
pressure of arterial oxygen $\left(\mathrm{PaO}_{2}\right)$ higher than $70 \mathrm{mmHg}$ and a partial pressure of arterial carbon dioxide $\left(\mathrm{PaCO}_{2}\right)$ lower than $70 \mathrm{mmHg}$, keeping the blood $\mathrm{pH}$ over 7.20. A positive end-expiratory pressure (PEEP) of $4-5 \mathrm{mmHg}$ was used in all patients. High-frequency oscillatory ventilation in patients with $\mathrm{CDH}$ due to former poor results in our clinic and due to lack of an extracorporeal membrane oxygenation (ECMO) machine at our centre or at any nearby centre to deliver the patient to at the time of this study, iNO was the therapy chosen for patients with failure of conventional therapy. iNO therapy was applied to patients with clinical signs of $\mathrm{PH}(>10 \%$ pre-postductal difference in pulse oximetry screening), hypoxemic respiratory failure despite optimal conventional ventilation $\left(\mathrm{PaO}_{2}<80 \mathrm{mmHg}\right.$ on $100 \%$ fraction of inspired oxygen $\left[\mathrm{FiO}_{2}\right]$ with optimal lung inflation), and a systolic pulmonary arterial pressure (PAP) higher than $40 \mathrm{mmHg}$ (all patients were evaluated with echocardiography). iNO was used for both early and late PH. Parental consent was obtained before initiation of the therapy. NOxBOX (Bedfont Scientific, Maidstone, UK), which is a machine able to deliver constant concentrations of NO via a non-rebreathing circuit and continuous flow, was used for iNO application. Continuous monitoring of $\mathrm{NO}$ and $\mathrm{NO}_{2}$ concentrations was performed via an electrochemical scanner, and a nitrogen dioxide level below 2 parts per million (ppm) was considered acceptable. Methemoglobin levels were also monitored continuously, using SpMet Radical-7R (Masimo Corporation, Irvine, CA, USA), and a value over $1 \%$ was never detected. iNO was started at a dosage of $20 \mathrm{ppm}$ and raised up to a maximum dosage of $45 \mathrm{ppm}$. iNO was ceased after weaning gradually to a dosage of $10 \mathrm{ppm}$ as the blood gases improved. The sildenafil and dopamine dosages remained the same throughout the therapy, and were stopped at the same time as iNO. All surviving patients had transfontanelle cranial ultrasonography, audiological assessment, retinal examination, and echocardiography to detect possible side effects of iNO before discharge. All patients received close follow-up; the mean follow-up duration was 38 (27-52) months.

Approval was obtained for retrospective review of the hospital records from the local ethics committee. To evaluate the success of iNO therapy, individual characteristics of the patients, ventilation parameters, and blood gas parameters were reviewed, and respiratory indices (the oxygenation index [OI] and the alveolar-arterial oxygen difference $\left[\mathrm{AaDO}_{2}\right]$ ) were computed and assessed with the outcome. Statistical analyses were performed using a Student's $t$ test and a Mann-Whitney $U$ test because of the small number of patients, and any results with a $p$ value less than 0.05 were considered statistically significant.

\section{Results}

Twenty-nine patients had a diagnosis of $\mathrm{CDH}$ at the time of study. Eight of these patients underwent nitric oxide therapy because of failure of conventional ventilation techniques, and five of these eight applications were successful. Considering the patients who underwent iNO therapy, the mean gestational age was $38(36-40)$ weeks, and the mean birth weight was $3,058(2,290-3,950) \mathrm{g}$. Two patients did not receive an antenatal diagnosis of $\mathrm{CDH}$, the others were diagnosed at 16-38 weeks of gestation (with a median of 24 weeks). One of the patients (who was diagnosed at 16 weeks of gestation) had an unsuccessful application of fetoscopic tracheal occlusion, and termination of pregnancy was offered to the parents in another clinic. Six patients had left-sided hernias, and two had right-sided hernias. There was stomach herniation in four patients and liver herniation in three. All patients were operated upon when they were hemodynamically stabilized and could maintain an optimal blood gas level, with $\mathrm{FiO}_{2}<40 \%$ and PIP $<25 \mathrm{mmHg}$. The mean timing of the operation was 3.75 days (2-7 days). Six patients underwent preoperative application of the therapy (at $0-1$ day), and two patients underwent late application of the therapy (at 9-12 days). The mean systolic PAP was $52.5 \mathrm{mmHg}(43-70 \mathrm{mmHg}$ ) before initiation of the therapy. None of the patients had structural congenital heart disease that might have cause intracardiac shunting (Table 1). Both patients with late $\mathrm{PH}$ were found to have a good response, whereas the patients with low birth weights were unresponsive to iNO therapy (Table 2); however, our patient group was too small to attribute a predictive feature to these variables regarding the success of the therapy.

All patients had deficient oxygenation despite optimal ventilatory support (mean $\mathrm{PaO}_{2}=46 \mathrm{mmHg}$ ). Before application of iNO, the mean $\mathrm{AaDO}_{2}$ was 555 (470-618) and the mean OI was 41.12 (14-62). No hypotension was observed during the therapy. The OI decreased by a mean of 7.6 and the $\mathrm{PaO}_{2}$ increased by a mean of $36 \mathrm{mmHg}$ within $60 \mathrm{~min}$ of commencing therapy. After cessation of the therapy, the mean $\mathrm{PaO}_{2}$ was $94.4 \mathrm{mmHg}$ (70-108), the mean $\mathrm{AaDO}_{2}$ was 141.6 (72-289), and the mean OI was 5 (3-8) (Table 2). The initial respiratory status of the patients did not seem to predict their response to iNO therapy $\left(p=0.14\right.$ for $\mathrm{PaO}_{2}, p=0.16$ for $\mathrm{AaDO}_{2}$, and $p=0.49$ for $\mathrm{OI}$ ); however, patients who had a good overall outcome were found to have rapid improvement after the first hour of therapy (pretreatment, mean $\mathrm{PaO}_{2}=$ $44.8 \mathrm{mmHg}$; after the first hour of therapy, mean $\mathrm{PaO}_{2}=96.8 \mathrm{mmHg}$ ), whereas patients with no response did not show a similar course (pretreatment, mean $\mathrm{PaO}_{2}=$ $37 \mathrm{mmHg}$; after the first of hour of therapy, mean 
Table 1 Individual characteristics of the patients

\begin{tabular}{lllllllll}
\hline $\begin{array}{l}\text { Patient } \\
\text { number }\end{array}$ & $\begin{array}{l}\text { Antenatal week at } \\
\text { diagnosis }\end{array}$ & $\begin{array}{l}\text { Gestational } \\
\text { week at birth }\end{array}$ & $\begin{array}{l}\text { Birth } \\
\text { weight }(\mathrm{g})\end{array}$ & $\begin{array}{l}\text { Side of } \\
\text { CDH }\end{array}$ & $\begin{array}{l}\text { Location of } \\
\text { stomach }\end{array}$ & $\begin{array}{l}\text { Day iNO was } \\
\text { started }\end{array}$ & $\begin{array}{l}\text { Systolic PAP before } \\
\text { iNO }(\mathrm{mmHg})\end{array}$ & $\begin{array}{l}\text { Outcome of } \\
\text { therapy }\end{array}$ \\
\hline 1 & 35 & 40 & 3,400 & Left & Thorax & 1 & 45 & Alive \\
2 & 38 & 39 & 3,950 & Left & Abdomen & 9 & 50 & Alive \\
3 & 17 & 38 & 3,070 & Left & Abdomen & 0 & 52 & Alive \\
4 & 16 & 36 & 3,100 & Right & Abdomen & 0 & 70 & Alive \\
7 & 20 & 37 & 3,150 & Left & Thorax & 12 & 55 & Alive \\
5 & None & 38 & 2,290 & Left & Thorax & 1 & 50 & Exitus \\
6 & 16 & 36 & 2,400 & Left & Thorax & 0 & 55 & Exitus \\
8 & None & 40 & 3,100 & Right & Abdomen & 0 & 43 & Exitus \\
\hline
\end{tabular}

$C D H$ congenital diaphragmatic hernia, $i N O$ inhaled nitric oxide, $P A P$ pulmonary arterial pressure

Table 2 Oxygenation parameters before inhaled nitric oxide (iNO) therapy, after 1 hour of therapy, and after cessation of therapy

\begin{tabular}{|c|c|c|c|c|c|c|c|c|}
\hline \multirow[t]{2}{*}{ Patient number } & \multicolumn{3}{|c|}{ Before therapy } & \multicolumn{2}{|c|}{ After 1 hour of therapy } & \multicolumn{3}{|c|}{ After cessation of therapy } \\
\hline & $\mathrm{PaO}_{2}$ & $\mathrm{AaDO}_{2}$ & OI & $\mathrm{PaO}_{2}$ & OI & $\mathrm{PaO}_{2}$ & $\mathrm{AaDO}_{2}$ & OI \\
\hline 1 & 74 & 567 & 14 & 88 & 20 & 108 & 72 & 4 \\
\hline 2 & 45 & 601 & 44 & 64 & 34 & 102 & 145 & 5 \\
\hline 3 & 45 & 586 & 56 & 159 & 14 & 106 & 69 & 3 \\
\hline 4 & 47 & 512 & 40 & 83 & 32 & 86 & 289 & 8 \\
\hline 7 & 43 & 618 & 37 & 90 & 24 & 70 & 133 & 5 \\
\hline 5 & 45 & 470 & 36 & 40 & 72 & Exitus & & \\
\hline 6 & 26 & 568 & 62 & 44 & 67 & Exitus & & \\
\hline 8 & 40 & 518 & 40 & 80 & 45 & Exitus & & \\
\hline
\end{tabular}

$\mathrm{AaDO}_{2}$ alveolar-arterial oxygen difference, $\mathrm{OI}$ oxygenation index, $\mathrm{PaO}_{2}$ partial pressure of arterial oxygen

$\mathrm{PaO}_{2}=54.6 \mathrm{mmHg}$ ) $\left[p=0.04\right.$ for $\mathrm{PaO}_{2}$ and $p=0.03$ for OI] (Table 2).

Except for the patient with a history of fetoscopic tracheal occlusion, all surviving patients were extubated, were discharged without oxygen dependency, and required no further therapy for $\mathrm{PH}$ after cessation of iNO. That particular patient, who had a number of risk factors with his history of unsuccessful fetoscopic tracheal occlusion, a right diaphragmatic hernia, a lung-to-head ratio of 0.8 , and a PAP of $70 \mathrm{mmHg}$, underwent a tracheotomy and was discharged with a home ventilator. He was able to come off the ventilator at 16 months of age, and his tracheotomy was closed at 21 months. Even that patient was described as having normal neurological development by his parents.

Another point worth mentioning is the safety of this therapy. No evidence of any short- or long-term adverse effects of iNO were observed. There was no sign of intraventricular hemorrhage on transfontanelle ultrasonography or retinopathy on retinal examination. The mean PAP was $28 \mathrm{mmHg}(25-32 \mathrm{mmHg})$ on echocardiography before discharge, and no patent ductus arteriosus was detected. Audiological assessment was also performed, and no hearing impairment (defined as a threshold of more than $40 \mathrm{~dB}$ ) was detected. Special neurodevelopmental tests were not applied to these patients; however, none of the patients' parents reported any developmental delay, and there was no history of seizures.

\section{Discussion}

$\mathrm{PH}$ is one of the most important aspects of $\mathrm{CDH}$ and still has a high mortality rate. Several studies have documented that iNO improves $\mathrm{PH}$ with causes other than $\mathrm{CDH}$ in newborns [2-8]. The Neonatal Inhaled Nitric Oxide Study Group trial also showed that iNO decreases the need for ECMO in patients with $\mathrm{PH}$ not caused by $\mathrm{CDH}$ [5], without any increase in neurodevelopmental impairment at 2 years of age [6]. There are no published data demonstrating why iNO therapy may not work in patients with $\mathrm{CDH}$, yet findings concerning $\mathrm{CDH}$ are inconsistent through the literature [9-11, 14]. Also, despite the results of the randomized trial, the Congenital Diaphragmatic Hernia Study Group reported that there has been a change in the management of infants with $\mathrm{CDH}$, with less frequent use of ECMO and greater use of iNO [11]. An easy and potent therapy such as iNO would be very valuable if it works for this major determinant of survival in patients with $\mathrm{CDH}$. 
We are certainly unable to claim definite conclusions with this retrospective study on a small patient group. The mean $\mathrm{AaDO}_{2}$ of the group was 555, and the mean OI was 41 . Considering the association of an $\mathrm{AaDO}_{2}$ score higher than 580 and a OI score higher than 40 with a mortality rate of $80 \%$ [19], the mortality rate of $37.5 \%$ seems to have been a relatively good outcome for this patient group.

Our patient group was too small for us to claim a reduced mortality rate in $\mathrm{CDH}$ patients; however, we would like to emphasize two important points that drew our attention.

The first was that, in line with the findings of previous reports, there was a strict and immediate distinction within the first hour of therapy between patients who would and those who would not subsequently benefit from it. Considering this early response and the more than $50 \%$ reduction in the mortality rate, we think that iNO therapy could be a first-line treatment option, with ECMO (which is a much more invasive and expensive therapy and is associated with a high complication rate) being reserved for use as an alternative if iNO therapy fails. In our opinion, 1 hour of delay would not hinder transfer to ECMO, and a short trial of iNO therapy is definitely worthwhile before exposing newborns to the risks of ECMO, in order to provide newborns with a safer treatment option.

The second point we wanted to draw attention to is that on reviewing our results and the literature, we thought that details of the various institutions' protocols might explain the inconsistent results reported in the literature. In different studies, better outcomes have been attributed to usage of cathecolamine [10] and sildenafil [2] individually. Our treatment protocol involved inotrope and sildenafil usage in all patients, which led us to speculate that it might have explained our better results. Both inotropes and sildenafil have been used in our clinic since before iNO therapy was introduced for $\mathrm{PH}$ in patients with $\mathrm{CDH}$. Dopamine has been used to augment cardiac performance, and sildenafil has been used for pulmonary vasodilatory effects. It has been suggested that decreased left ventricular performance is common and may be an important determinant of responsiveness to iNO therapy in $\mathrm{CDH}$ [8]. Shiyanagi et al. [10] reported better results when they switched their therapy from prostaglandins to cathecholamines in addition to iNO. Keller et al. [20] reported better results with use of iNO and phosphodiesterase inhibition. We think that use of dopamine (which augments left ventricular performance) and sildenafil (which has pulmonary vasodilator effects) might increase the response to iNO therapy; therefore, we attribute the reduction in the mortality rate to our institution's protocol involving use of dopamine and sildenafil together. We do not have enough data to confirm this statement; however, it might be the key to the conflicting results of studies involving iNO usage in $\mathrm{CDH}$, and it deserves further attention.

\section{Conclusion}

The early response to iNO therapy in patients with $\mathrm{PH}$ due to $\mathrm{CDH}$ seemed to predict the overall outcome; therefore, a "short trial" of iNO therapy should be considered as the first-stage option before subjecting newborns to ECMO. Institutional protocol differences might be the cause of the conflicting findings reported in the literature, and this requires further investigation.

Conflict of Interest Statement There was no financial support for this study, and none of the authors participating in this study has any conflict of interest that might have influenced the study.

Open Access This article is distributed under the terms of the Creative Commons Attribution Noncommercial License which permits any noncommercial use, distribution, and reproduction in any medium, provided the original author(s) and the source are credited.

\section{References}

1. Ignarro IJ, Buga GM, Wood KS, et al. Endothelium derived relaxing factor produced and released from artery and vein is nitric oxide. Proc Natl Acad Sci. 1987;84:9265-9.

2. Kinsella JP, Truog WE, Walsh WF, et al. Randomized, multicenter trial of inhaled nitric oxide and high-frequency oscillatory ventilation in severe, persistent pulmonary hypertension of the newborn. J Pediatr. 1997;131:55-62.

3. Wessel DL, Adatia I, Van Marter LJ, et al. Improved oxygenation in a randomized trials of inhaled nitric oxide for persistent pulmonary hypertension of the newborn. Pediatrics. 1997;100(5):e7.

4. Davidson D, Barefield ES, Kattwinkel J, et al. Inhaled nitric oxide for the early treatment of persistent pulmonary hypertension of the term newborn: a randomized, double-masked, placebo-controlled, dose-response, multicenter study. Pediatrics. 1998;101:325-34.

5. Neonatal Inhaled Nitric Oxide Study Group (NINOS). Inhaled nitric oxide in full-term and nearly full-term infants with hypoxic respiratory failure. N Engl J Med. 1997;336:597-604.

6. Neonatal Inhaled Nitric Oxide Study Group. Inhaled nitric oxide in term and near-term infants: neurodevelopmental follow-up of the Neonatal Inhaled Nitric Oxide Study Group (NINOS). J Pediatr. 2000;136:611-7.

7. Clark RH, Kueser TJ, Walker MW, et al. Low-dose nitric oxide therapy for persistent pulmonary hypertension of the newborn. N Engl J Med. 2000;342:469-74.

8. John P, Kinsella D, Dunbar I. Pulmonary vasodilator therapy in congenital diaphragmatic hernia: acute, late, and chronic pulmonary hypertension. Semin Perinatol. 2005;29:123-8.

9. NINOS. Inhaled nitric oxide and hypoxic respiratory failure in infants with congenital diaphragmatic hernia. Pediatrics. 1997;99(6):838-45.

10. Shiyanagi S, Okazaki T, Shoji H, et al. Management of pulmonary hypertension in congenital diaphragmatic hernia: nitric 
oxide with prostaglandin-E1 versus nitric oxide alone. Pediatr Surg Int. 2008;24:1101-4.

11. Congenital Diaphragmatic Hernia Study Group. Treatment evolution in high-risk congenital diaphragmatic hernia: ten years' experience with diaphragmatic agenesis. Ann Surg. 2006;244(4): 505-13.

12. Sebald M, Friedlich P, Burns C, et al. Risk of need for extracorporeal membrane oxygenation support in neonates with congenital diaphragmatic hernia treated with inhaled nitric oxide. J Perinatol. 2004;24:143-6.

13. Irish MS, Kapur P, Gliek PL. Additional considerations for inhaled nitric oxide therapy in congenital diaphragmatic hernia. Pediatr Surg Int. 1997;12:466-7.

14. Haroon J, Chamberlain RS. An evidence-based review of the current treatment of congenital diaphragmatic hernia. Clin Pediatr. 2013;52:115-24.

15. Henneberg SW, Jepsen S, Andersen PK, et al. Inhalation of nitric oxide as a treatment of pulmonary hypertension in congenital diaphragmatic hernia. J Pediatr Surg. 1995;130:853-5.
16. Karamanoukian H, Glick PL, Zayek M, et al. Inhaled nitric oxide in congenital hypoplasia of the lungs due to diaphragmatic hernia or oligohydramnios. Pediatrics. 1994;94(5):715-8.

17. Nishit S, Jacob T, Exler R. Inhaled nitric oxide in congenital diaphragmatic hernia. J Pediatr Surg. 1994;29(8):1010-5.

18. Bos AP, Tibboel D, Koot VC. Persistent pulmonary hypertension in high-risk congenital diaphragmatic hernia patients: incidence and vasodilator therapy. J Pediatr Surg. 1993;28:1463-5.

19. Hirschl RB, Bartiert RH. Extracorporeal life support for cardiopulmonary failure. In: Coran AG, Adzick NS, Krummel TM, editors. Pediatric surgery. 7th ed. Philedelphia: Elsevier; 2012. p. 123-32.

20. Keller RL, Moore P, Teitel D, et al. Abnormal vascular tone in infants and children with lung hypoplasia: findings from cardiac catheterization and the response to chronic therapy. Pediatr Crit Care Med. 2006;7:589-94. 